\title{
Constructing Local Thainess-Based English Teaching Materials: Southern Thailand
}

\author{
Budsaba Kanoksilapatham
}

\begin{abstract}
In response to the influx of English influence which potentially leads to national identity subjugation, coupled with the prevalent importance for a nation's citizens to be competent in English, this paper highlights the role of English education in Thailand as an appropriate channel to address the imminent need to not only develop English competence but also maintain and preserve Thai national identities. Given the pivotal role of elementary education as the grassroots of the entire educational paradigm, this study has the objective of developing a set of English instructional materials for Grade 4 students. Specifically contextualized in southern Thailand, prominent and distinguishing features of the teaching materials created lie in the focus placed on southern Thai features. To assure that the constructed materials reflect the actual needs of the community, a questionnaire consisting of a list of 46 tourist attractions in southern Thailand was administered to local residents to elicit the top eight most popular tourist attractions in Southern Thailand. The list of eight attractions in turn provides a basis for the construction of the eight English lessons. Conforming to the same format, individual lessons begin with 10 vocabulary items associated with each lesson topic, followed by 6 to 8 sentences integrating all of the 10 words. Finally, the entire set of lessons was validated by English school teachers in southern Thailand for content accuracy and the appropriateness of the English for Grade 4 students. This study represents one pedagogical attempt to ameliorate young Thai learners' English and whilst inculcating into them Thainess features.
\end{abstract}

Index Terms-Teaching materials, elementary students, preservation, English lessons, southern Thainess.

\section{INTRODUCTION}

In the world of highly developed technology and in the borderless era, the English language has become increasingly important in all aspects of people's daily lives. Despite the positive connotations attached to these trends, some scholars are concerned about the current scenario. They envisage that in the near future, it is highly likely that the influx of the English language could lead to detrimental consequences, including the menace to, and subjugation of, national culture. Given the number of younger generations in individual countries who are, to a certain extent, vulnerable to the influx of English related influences and their readiness to accept these influences, these scholars deem it is time to do something to rightly respond to this calling.

It is also undeniable that the English language has attained the status of an international language and become a prerequisite of all citizens. The role of English in the job market is even more succinct when graduates with limited

Manuscript received August 14, 2019; revised September 17, 2019.

Budsaba Kanoksilapatham is with the Silpakorn University, Thailand (email: kanoksib@gmail.com).
English competence are likely to be at a disadvantage when competing for jobs. In the context of Thailand, a look at Thai citizens' English performance reflects a bleak situation because Thai learners' English performance has been at an unacceptable level for many years. This phenomenon is evident when looking at the results of national and international tests [1]-[3]. In short, the need to improve Thai citizens' English has constantly been at the top of the national agenda, and clearly necessitates educational upheaval.

This paper represents an initial attempt to address the dire need to preserve and maintain Thai culture and to respond to the national call to improve Thai learners' English ability. Specifically, this paper highlights the realm of English education as a venue to satisfy those needs in the context of southern Thailand. That is, it is anticipated that English teaching materials focusing on southern Thainess will contribute to the maintenance of southern Thai culture and serve as an effective instrument to improve southern Thai learners' English.

\section{A. Culture and Language Learning}

It is established that language and culture are closely embedded or related. Learners cannot succeed in language learning if they are not aware of cultural features pertaining to the target language [4]-[8], and [9]. As a consequence, a number of English textbooks deliberately integrate the cultural features of English native speakers in order to make sure that the learners' exposure to the target culture is enhanced. Pedagogically, teachers of English are encouraged to introduce the target cultural features when opportunities permit by bringing, for example, realia or objects to the classroom such as authentic city maps, brochures, or restaurant menus. They may also integrate multimedia featuring the target culture, to compensate for the students' lack of cultural input or exposure. In short, language learners need to be not only linguistically knowledgeable but also culturally knowledgeable of the target language. It is expected that these two bodies of knowledge can complement each other, contributing to a successful language learner and effective communicator.

\section{B. Target Culture or Local Culture?}

This section scrutinizes a common practice, emphasizing English speakers' culture in English language education. To make sure that such integration is maximally beneficial, a number of variables need to be seriously considered, including the learners' age, experience, as well as learning contexts. In this regard, exposing young learners to English speaking native cultures may not have a beneficial result. It is established that in order to be effective communicators, learners are required to have a clear understanding of their 
own native culture prior to exposure to the target language culture [4]. The justification lies in the fact that the learners need to be not only knowledgeable of the target culture but also able to compare and contrast cultural features pertaining to the target language and other languages including their native language.

However, given the young age of the learners, such a practice can be cognitively demanding and too daunting. Therefore, to provide a scaffold for the learners - especially young learners, English teaching materials that are associated with their own national culture are likely to ease the process of language learning. That is, with the exposure to the content of the materials being relevant to their daily lives and environment, they thus tend to experience no difficulty connecting with the lessons, resulting in augmented motivation and learning outcomes. In this regard, the selection of local culture to be included in the lessons is determined partly by the age of language learners. Similarly, for older learners of English, possessing a good grasp of their local culture will provide them with some content to generate, compare, and contrast. In addition, they will also be better equipped to express themselves. In so doing, Thai learners can develop to become quality citizens, contributing to the sustainable development of the country.

\section{What Aspects of Local Culture?}

As established in the previous section, local culture needs to be primarily instilled in young learners. However, a look at the notion of culture can be quite fascinating. The culture of a county is complex, comprising of a myriad of constructs and manifestations, including language, customs, tourist attractions, foods, festivals, superstitions, lifestyle, clothing, values, traditions, beliefs, arts, and morals. In fact, almost anything around us can be considered culture.

An emerging question is, if local culture is to be used as a focus for young learners, what aspects of local culture are appropriate for this particular group of learners. Although no specific criteria is available yet to determine which aspects of culture are appropriate for young learners, it is known that cultural constructs can generally be divided into two categories: concrete and abstract cultural features. In this regard, concrete cultural features seem to be appropriate and more favorable for young learners because they are comparatively less cognitively overloading for the learners to understand. Moreover, concrete cultural features do not seem to require a tremendous effort from the learners in order to be appreciated. Among all of the cultural constructs which are concrete, tourist attractions seem to be one of the best alternatives because they are concrete, visible, and transparent. Additionally, they will appeal to young learners who are interested and generally excited about the world around them.

Given the learners' relatively young age and limited exposure and opportunities of this study, local tourist attractions seem to offer more learning opportunities, as they are in their environment, and thus the learners will probably be familiar with the attractions, even though they might not have had a chance to visit them. At this juncture, the learners' environment receives additional attention. To make the lessons more manageable and within the range of their interest and English competence, this paper focuses on integrating tourist attractions in southern Thailand into English teaching materials developed for young learners of English in southern Thailand.

\section{METHODS}

The objective of this study is to systematically construct a set of instructional English materials for Grade 4 students in southern Thailand. These materials are unique because they were developed based on the needs of southern Thailand residents. The following sections describe the procedural steps regarding how the teaching materials were designed and developed.

\section{A. Needs Analysis}

It is commonly known that each part of a country has its own set of unique cultural features. Similarly, Thailand has a number of national tourist attractions: some are more or less prominent than others. In this regard, to make sure that the teaching materials to be developed satisfy the needs of southern Thailand residents, a questionnaire was devised to elicit a number of potential tourist attractions that could subsequently be turned into English lessons. Initially, from an Internet search of southern Thailand tourist attractions, a total of 46 attractions scattered in southern Thailand was obtained, and thus listed on the questionnaire to be implemented to local residents in 14 southern provinces: 100 copies of the questionnaire for each province, yielding 1,400 copies distributed throughout the southern part of Thailand. The question asked on the questionnaire was: "What are the top eight tourist attractions of which the young generation in southern Thailand should be aware?" Based on the eight highest frequency counts, eight lessons corresponding with these tourist attractions were developed for Grade 4 students in southern Thailand.

\section{B. Teaching Material Development}

The eight tourist attractions with the highest votes as described above were used as the lesson topics which were developed into eight corresponding English lessons for Grade 4 southern Thai students. At this juncture, it should be noted that a number of constraints needed to be taken into consideration while developing these English lessons.

First, the learners' limited English competence precludes the use of certain grammatical constructions or features such as passive construction, compound sentences, and complex sentences. Next, it is obvious that the learners' vocabulary repertoire is quite limited; therefore, the choice of words must be carefully selected to ensure that the words are not too daunting or challenging for the learners. Additionally, the young learners' possible limited attention span does not allow the materials to be too informationally dense. This means that a number of language tasks and activities are needed to allow learners to practice language use. Finally, a number of material development theories or frameworks are consulted to maximize the learning outcome benefits [9], [10]. Given the unique characteristics of Generation $\mathrm{Z}$ learners, these lessons also need to be accompanied by multimedia materials to keep these young learners motivated and to sustain their attention span. Additionally, to make sure that there is a means to measure or assess their learning, 
a set of tests were constructed. Moreover, the multimedia materials associated with the lessons and produced at the actual tourist attractions enable the English teachers to expose the learners to the outside world by using videos. Based on these requirements and constraints while developing the instructional materials, all of the eight lessons were developed. Following the same format, each lesson is principally divided into two major parts: 1 . ten vocabulary items and 2 . six to eight sentences for reading, integrating all of the focused vocabulary items. To supplement the lessons, multimedia materials were produced To elaborate and to illustrate, the following sections provide a detailed description of individual parts of the lessons.

\section{1) Vocabulary}

Each lesson begins with a set of ten words, accompanied by their translation in Thai. To obtain a list of ten words for each lesson, initially, a short description pertaining to individual attractions was compiled from different sources and documents. Based on the compiled description, a number of words that bear crucial contribution to the description were listed and subsequently selected to be included in the lessons. At this juncture, the word selection was carefully executed to make sure that the words are not too difficult for the young learners.

\section{2) Sentence reading}

Subsequent to the vocabulary part is the sentence reading part containing six to eight sentences. This part aims to purposefully reinforce the learners' understanding of individual vocabulary items introduced in the previous part of the lesson. That is, the sentences are to demonstrate the use of words in the context of southern Thailand. In short, these sentences are to perform the function of presenting important accounts of individual tourist attractions. It needs to be noted that in these sentences, the focused words are highlighted to attract the learners' attention to notice the vocabulary used in context.

3) Supplementary materials

To accompany the instructional lessons, three sets of supplementary materials were created: the corresponding handouts, multimedia materials, and testing materials.

The handouts developed to accompany individual lessons consists of the two parts that were described earlier: the vocabulary part and the reading section, respectively. To make the handouts more attractive and to facilitate the learning process, six pictures corresponding to the lesson content were concurrently presented.

As mentioned earlier, the Generation $\mathrm{Z}$ learners seem to be attracted to all types of multimedia materials. Thus, multimedia materials corresponding to individual lessons are deemed beneficial. The multimedia materials were produced at the actual tourist attraction sites. Each set of multimedia materials is about eight to ten minutes long, with the set of reading sentences running at the bottom of the screen. If needed, a recording of the sentences read by a native speaker can be played to the learners. The use of mutimedia materials was usually after reading the sentences. However, multimedia materials could be played when the teachers deemed appropriate or at the request of the students

At this juncture, in addition to the teaching materials, two sets of assessment tools were constructed. Given the objectives of this study are to incalcate local culture into the young learners' local cultural awareness and to improve their English, the two sets of tests include a southern Thainess test and an English vocabulary test.

The southern Thainess test has the objective of assessing the learners' cultural knowledge. Due to this focus, the language used in this test is Thai. The 40-item test was designed to accommodate the young age of the learners; five items were generated from each lesson. The test required them to complete each blank in one of the 40 Thai statements. No penalty was executed for spelling mistakes as long as the answers are understood. All of the questions were generated from the content of the lessons.

As for the vocabulary test, similar to the southern Thainess test, five items were generated from each lesson, yielding a total of 40 items. In this test, the learners were required to choose one of the four different pictures that matches the word pronounced twice by a teacher. The pictures were carefully selected to represent the four alternatives. All of the described materials were validated by Grade 4 teachers of English and social sciences for content accuracy and difficulty level.

In short, this section describes the various components of the teaching materials: the lesson consisting of two parts of vocabulary and reading sentences, the handouts as a scaffold, the multimedia materials to provide authentic input to the learners, and finally, the assessment tools to measure the learners' knowledge of southern Thainess or southern cultural features and associated English vocabulary.

\section{RESULTS}

This section presents the results regarding the English lessons developed based on cultural features in southern Thailand.

\section{A. Needs Analysis Results}

After the administration of the questionnaire to elicit the potential topics to be developed into English teaching materials to local residents in southern Thailand, a total of 1,400 copies were returned for further analysis. Based on the frequency counts, the top eight highest votes are shown in Table I.

TABLE I: EIGHT TOURIST ATTRACTIONS

\begin{tabular}{|c|l|c|}
\hline Rank & \multicolumn{1}{|c|}{ Tourist Attraction (Province) } & Frequency \\
\hline 1 & Samila Beach (Songkhla) & 655 \\
\hline 2 & $\begin{array}{l}\text { Samui Island (Surathani) + Similan Islands } \\
\text { (Pang Nga) }\end{array}$ & 644 \\
\hline 3 & $\begin{array}{l}\text { Wat Phra That (Nakhon Si Thammarat + The } \\
\text { Central Mosque (Pattani) }\end{array}$ & 536 \\
\hline 4 & Songkhla Zoo (Songkhla) & 529 \\
\hline 5 & Cheow Lan Dam (Suratthani) & 492 \\
\hline 6 & Khiriwong (Nakhon Si Thammarat) & 478 \\
\hline 7 & Emerald Cave (Trang) & 441 \\
\hline 8 & Phromthep Cape (Phuket) & 439 \\
\hline
\end{tabular}

At this juncture, it needs to be noted that the landscape of southern Thailand is somewhat unique. Due to the long strip of the southern landscape, this region is usually compared to the handle of an axe. In fact, this part is flanked by two 
bodies of water on the east and west of the region: The Gulf of Thailand and The Andaman Sea, respectively. Consequently, a number of tourist attractions involve beaches and sea landscapes. As shown in Table I, five out of eight spots are related to sea landscapes, prominent geographical features that can be anticipated in southern Thailand. However, to make sure that the lessons display the diversity of the region, and the students could be exposed to such varieties, some tourist attractions were combined into a single lesson. For instance, Lesson 2: Samui and Similan Islands are in fact two separate items on the questionnaire: Samui Island with 644 votes, ranked 2 and Similan Islands with 361 votes, ranked 14. Given the potential overlapping set of words shared by these two topics, they were combined as one single lesson of Lesson 2 to represent the two major islands on the east and west coasts of Thailand.

As suggested and cautioned by [11], [12], and [13], the local culture topics should not be in conflict with the corresponding local characteristics. Given that the Muslim culture is prevalent in the area and to avoid possible discord that might arise among the southern learners, the Central Mosque in Pattani (279 votes, ranked 16) was combined with Wat Mahathat (536 votes, ranked 3) to keep the religious topic balanced and to authentically reflect the harmony of two religions in the area.

\section{B. Teaching Materials Developed}

This section focuses on the lessons developed based on the methodology described in the previous section. Based on the eight tourist attractions above, eight corresponding English lessons were developed. Initially, crucial information about each tourist spot was searched from all sources available including the Internet, tourism brochures, and government documents to form a short description of each site, which was in turn condensed to form the content of the lessons. Then, two school teachers of social science and English in a southern school were invited to validate the lesson content for accuracy and current relevance. Extraneous or irrelevant elements were deleted to contribute to a precise description of the site.

\section{1) Vocabulary part of the lesson}

Subsequently, given the pivotal role of vocabulary that drives the content of the language and particularly the lesson, each lesson was designed to start with ten vocabulary items which were carefully selected to make sure they are representative of the site description. These vocabulary items are in turn accompanied by their corresponding Thai translations to facilitate the learners' vocabulary learning.

To illustrate what the vocabulary part of a lesson looks like, Lesson 2: Samila Beach was exemplified. Table II presents a word list directly pertaining to the content of the lesson about Samila Beach.

TABLE II: WORD LIST FOCUSED IN THE LESSON

\begin{tabular}{|c|c|c|}
\hline Number & Word & Meaning \\
\hline 1. & beach & ชายหาด \\
\hline 2. & town & เมือง \\
\hline 3. & lake & ทะเลสาบ \\
\hline 4. & sand & ทราย \\
\hline
\end{tabular}

\begin{tabular}{|c|c|c|}
\hline 5. & pine & ต้นสน \\
\hline 6. & tree & ต้นไม้ \\
\hline 7. & island & เกาะ \\
\hline 8. & far & ไกล \\
\hline 9. & mermaid & นางเงือก \\
\hline 10. & statue & รูปปั้น \\
\hline
\end{tabular}

\section{2) Sentence reading of the lesson}

As previously described, the word list of individual lessons is followed by a set of six to eight sentences, containing the focused words highlighted. Fig. 1 displays the reading sentences with the focused words highlighted in the lesson.

1. Samila Beach is in Songkhla.

2. It is a part of Songkhla town.

3. Samila Beach is near Songkhla Lake on the Gulf of Thailand.

4. The sand of Samila Beach is white.

5. Many pine trees are at the beach.

6. Nu Island and Maew Island are not far from the beach.

7. A mermaid statue is at the beach.

Fig. 1. Word list in sentences.

In order to expose the learners to the accounts of each site, a reading section containing six to eight simple sentences of 50-65 words in total is after the vocabulary part. The content of this reading section incorporates the ten vocabulary items previously presented, covering specific information about individual tourist attractions from diverse perspectives, such as geographical details, historical accounts and highlighted activities. In this part of the lesson, all the words presented in the vocabulary section are included and highlighted in the sentences.

In order to accommodate the young learners' limited English proficiency, certain syntactic constructions such as passive construction, extraposed ' $i t$ ' construction, or complex sentences were intentionally avoided. Again, two school teachers of English and social sciences were invited to validate the language use in the reading section to make sure that the language used stays within the possible range of the target students' knowledge. After this validation, two native speakers checked the language use for accuracy.

\section{3) Handouts}

In addition to the content of the English lessons extracted from the questionnaire results, supplementary materials were produced to supplement the instructional innovation. The first supplementary material was PowerPoint presentations. To scaffold the learners' learning, the materials of the lessons are presented in a Powerpoint format to the students alongside a Thai translation and audio tracks of pronunciation by an English native speaker. It is expected that the set of colorful slides containing pictures taken at the actual sites of the tourist attractions will make the students motivated to learn and appreciate their local Thainess.

This set of learning and teaching materials was designed to be implemented before the students viewed the video clips (to be described in the following paragraph). The PowerPoint presentations consisted of a picture alongside the title of a lesson named after each tourist site in both the English and Thai languages, followed by a set of ten English 
vocabulary items with a Thai translation, an identification of the location of the tourist site shown on a map of southern Thailand, and six to eight simple English sentences accompanied by colorful photos pertaining to the content of each English sentence. Fig. 2 features a set of Powerpoint slides prepared as a handout for the students to accompany the lesson on Samila Beach.
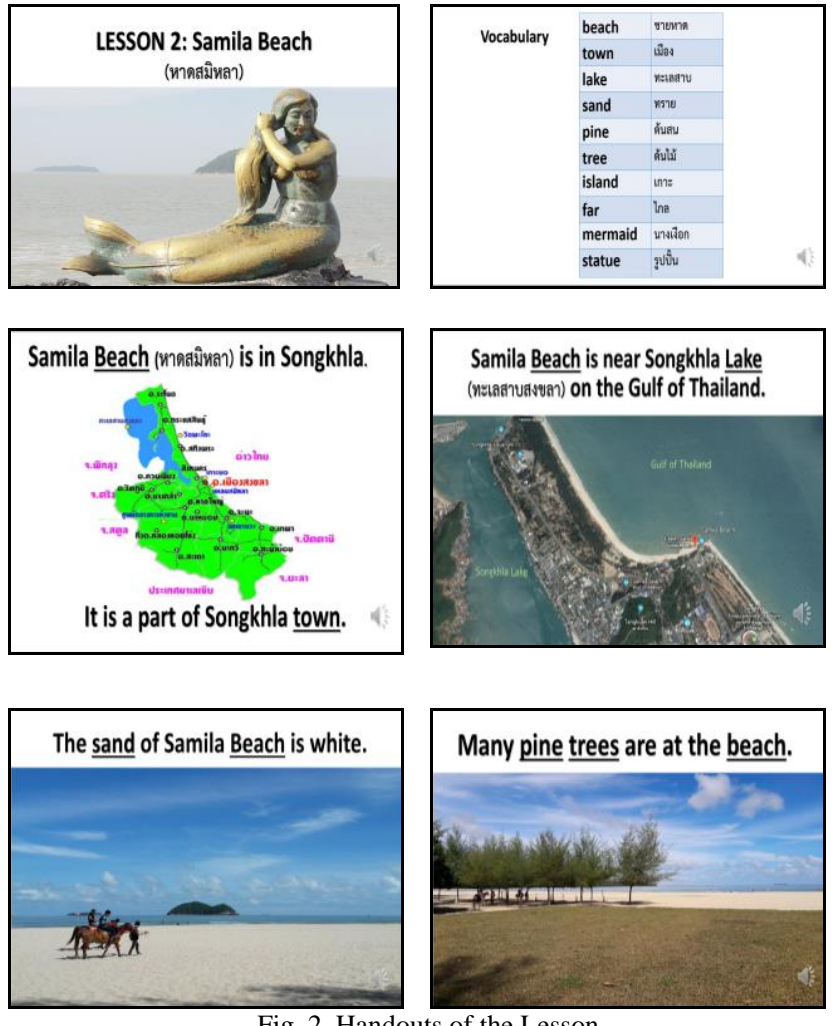

Fig. 2. Handouts of the Lesson.

\section{4) Multimedia materials}

At this juncture, to compensate for certain students' limited opportunities of exposure to these tourist sites due to their young age and possibly financial situation of the family that might preclude them from visiting the sites, the lessons developed are accompanied by corresponding multimedia materials. In addition, the materials contribute to the enhanced authenticity of the lessons.

These multimedia materials were the production of eight video clips from the actual tourist sites of the tourist attractions. These clips highlight the visual features of the content of the lessons. Each set of multimedia materials lasts about eight to ten minutes (Fig. 3). A description of the site was voiced over in Thai and eventually with running English texts used in the reading section so that they can reinforce each other as far as learning is concerned.

\section{1) Assessment materials}

Generally, language learning needs to be accompanied by certain tasks to monitor and reinforce the language learned. For this young group of learners, two major sets of tests were designed and developed to assess their knowledge of southern Thainess and English vocabulary associated with individual lessons. The southern Thainess knowledge test consists of 40 items; five items were constructed from the accounts of each lesson. Given the focus is placed on southern Thainess knowledge, the language used in this test is Thai. This test requires the students to complete the missing information in Thai.
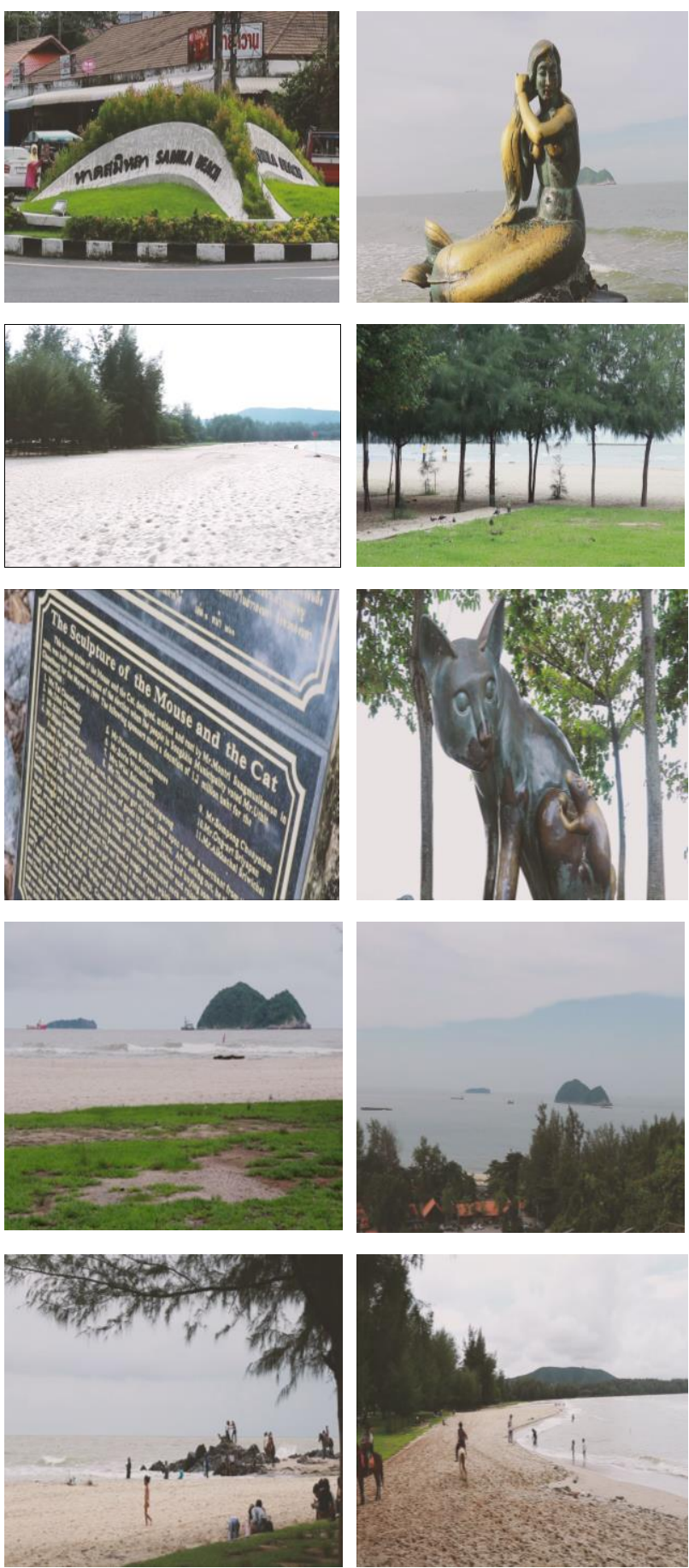

Fig. 3. Multimedia materials

To illustrate, Fig. 4 displays the five test items pertaining to Lesson 2: Samila Beach, translated into English.

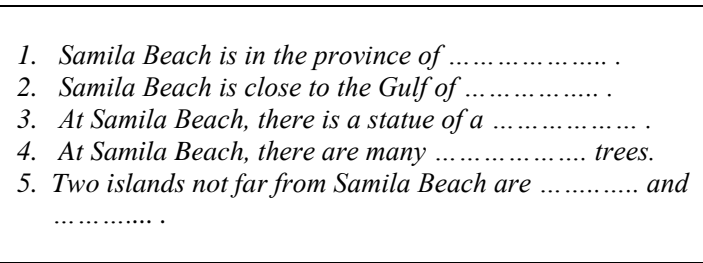

Fig. 4. Thainess test.

The other test focusing on the learners' knowledge of English vocabulary items associated with the eight lessons was developed. Again, given the young age of the learners, the test is not too cognitively challenging, consisting of 40 
items. Similar to the local Thainess knowledge test, five items represent each of the eight lessons. For each item, four colorful pictures were selected and only one picture matches the word heard. The target word was pronounced clearly and slowly twice and the students simply choose the corresponding picture.

The vocabulary test as shown in Fig. 5 displays an item with the target word 'beach'. After hearing the word said twice by a native speaker, the students choose one of the four pictures that matches the word heard. The answer is the picture on the top right hand corner.
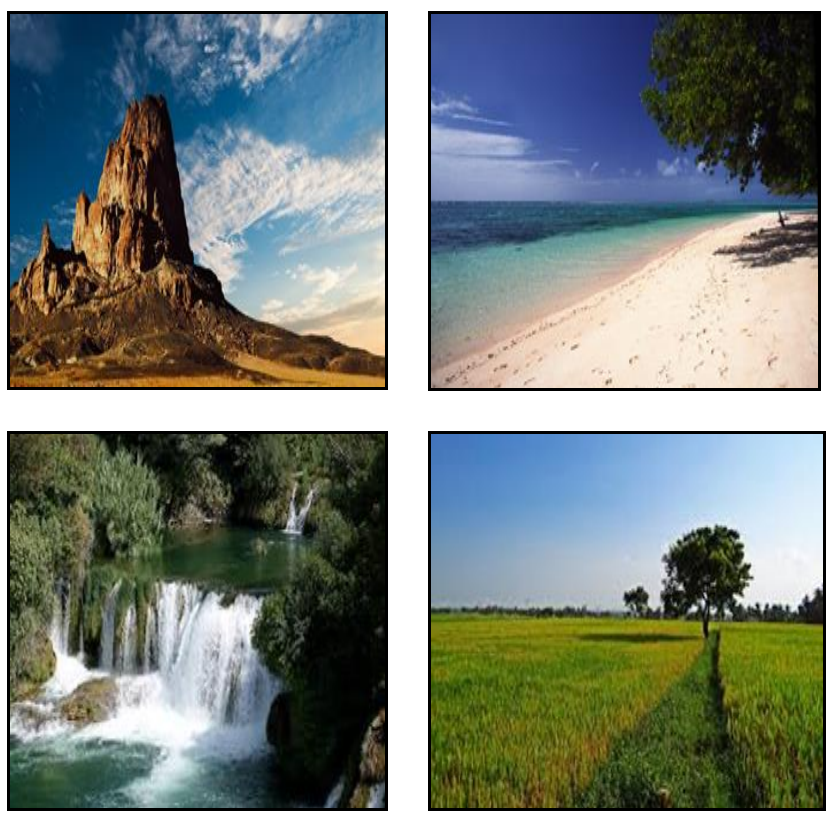

Fig. 5. Vocabulary test.

In short, this section presents the entire set of eight lessons focusing on southern Thainess features. Individual lessons consist of two major parts: vocabulary and sentence reading. To facilitate learners and teachers in the instructional process, handouts with pictures of the tourist attractions were also created. To keep the learners motivated and enhance their exposure to the input, multimedia materials were constructed. Finally, to monitor the learners' knowledge, two sets of tests were constructed focusing on their cultural knowledge and English vocabulary.

\section{DISCUSSION}

This paper aims to highlight the realm of English language teaching as a venue to address concerns that national culture is being menaced or subjugated by a more influential culture, for example that of English-speaking peoples. This paper has demonstrated how the two issues (maintaining local culture and promoting global English) which seem on the surface to be contradictory can actually be mutually complimentary. As demonstrated in this paper, the lessons developed based on southern Thainess features can be employed as supplementary materials, in tandem with existing textbooks. It is anticipated that these developed materials can enhance these young learners' cultural awareness, citizenship values, and sense of national understanding. The remaining issues to be empirically validated and tested is whether the constructed materials can indeed promote local culture awareness and English competence. Nevertheless, a number of pedagogical implications and considerations can be generated from this entire set of materials.

\section{ACKNOWLEDGMENT}

This research work was supported by the TRF Senior Scholar Fund provided by the Thailand Research Fund or TRF (Grant No. RTA5880007). The author wishes to express heartfelt appreciation to the research team members and school teachers who have contributed to the completion of the English teaching materials development.

\section{REFERENCES}

[1] B. Kanoksilapatham, "Promoting global English while forging young northeastern Thai learners' identity," 3L: The Southeast Asian Journal of English Language Studies, vol. 22, no. 3, pp. 127-140, 2016

[2] B. Kanoksilapatham and P. Channuan, "EFL learners' and teachers" positive attitudes towards local community-based instruction,' Indonesian Journal of Applied Linguistics, vol. 7, no. 3, pp. 514-515, 2018.

[3] B. Kanoksilapatham and T. Suranakkharin, "Celebrating local, going global: Use of northern Thainess-based English lessons," Asia TEFL, vol. 15 , no. 2, pp. 292-309, 2018

[4] M. Byram, "Cultural awareness as vocabulary learning," Language Learning Journal, vol. 16, no. 1, pp. 51-57, 1997.

[5] M. Byram and M. Fleming, Language Learning in Intercultural Perspective Approaches through Drama and Ethnography, Cambridge: Cambridge University Press, 1998.

[6] J. Foley and L. Thompson, Language Learning, London: Arnold, 2003.

[7] K. Risager, Language and Culture: Global Flows and Local Complexity, Cambridge: Cambridge University Press, 2008.

[8] L. Sercu, "The future of intercultural competence in foreign language education: Recommendations for professional development, educational policy and research," in Foreign Language Teachers and Intercultural Competence: An International Investigation, L. Sercu, Ed. Clevedon: Multilingual Matters, 2005, pp, 60-181.

[9] B. Tomlinson, Material Development in Language Teaching, Cambridge: Cambridge University Press, 2011.

[10] R. Schmidt, "Awareness and second language acquisition," Annual Review of Applied Linguistics, vol. 13, pp. 206-226, 1993.

[11] A. S. Fenner, "Cultural awareness," in Approaches to Materials Design in European Textbooks: Implementing Principles of Authenticity, Learner Autonomy, and Cultural Awareness, A. B. Fenner and D. Newby, Eds. Graz: European Centre for Modern Languages, 2000.

[12] T. T. T. Nguyen, "Integrating culture into language teaching and learning: Learner outcomes," The Reading Matrix: An International Online Journal, vol. 77, pp. 145-154, 2017.

[13] K. Risager, Language and Culture Pedagogy, Clevedon: Multilingual Matters, 2008.

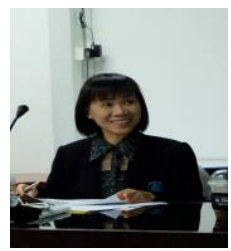

Budsaba Kanoksilapatham was born in Samut Sakhon, Thailand. She completed her bachelor's degree in English at Chulalongkorn University, Thailand. Later, she earned her master's degree in linguistics and English as a foreign language (EFL) at Southern Illinois University at Carbondale and subsequently her doctoral degree in Linguistics (Concentration: applied linguistics) at Georgetown University, Washington DC, USA in 2003

She is currently a professor at the English Department, Faculty of Arts, Silpakorn University, Nakhon Pathom, Thailand. Her most recent books are pronunciation in action and English Sociolinguistics at Work. Her research articles published in international journals including English for Specific Purposes, the IEEE Transactions on Professional Communication, and others. Professor Budsaba Kanoksilapatham has also served as a reviewer for a number of academic journals and has been a keynote speaker at more than 30 national and international conferences. 